\title{
Maximal physiological responses during arm cranking and treadmill wheelchair propulsion in T4-T6 paraplegic men
}

\author{
EM Gass, LA Harvey and GC Gass \\ Rehabilitation Research Centre, Faculty of Health Sciences, The University of Sydney, New South Wales; \\ Department of Physiotherapy, Prince Henry Hospital, Sydney, Australia
}

\begin{abstract}
The aim of the study was to compare the exercise responses during maximum wheelchair propulsion on a motor driven treadmill (TM) and maximum arm cranking (AC) in a homogenous group of nine paraplegic men with clinically complete spinal cord lesions between T4 and T6. The test order for each ergometer was random and time between the two ergometer tests was 3-7 days. All experiments were conducted in an air conditioned environment $\left(23^{\circ} \mathrm{C} \mathrm{DB}, 18^{\circ} \mathrm{C} \mathrm{WB}\right)$. The highest $\mathrm{VO}_{2}$ recorded during the final minute of arm cranking $\left(1.65 \pm 0.14 \mathrm{lmin}^{-1}\right)$ and wheelchair propulsion on the treadmill $(1.72 \pm$ $0.10 \mathrm{lmin}^{-1}$ ) was not significantly different. There were no significant differences in heart rate during the final minute of arm cranking $\left(177 \pm 3 \mathrm{~b} \mathrm{~min}^{-1}\right)$, and wheelchair propulsion on a motor driven treadmill $\left(177 \pm 4 \mathrm{~b} \mathrm{~min}^{-1}\right)$, nor were there any significant differences in minute ventilation (STPD) between AC $\left(52 \pm 6.61 \mathrm{~min}^{-1}\right)$ and TM $\left(56.1 \pm 4.81 \mathrm{~min}^{-1}\right)$. The $\dot{\mathrm{V} C O} \mathrm{lmin}^{-1}$ for AC $\left(2.00 \pm 0.20 \mathrm{lmin}^{-1}\right)$ and TM $\left(2.00 \pm 0.121 \mathrm{~min}^{-1}\right)$ was also not significantly different. The present study found that, unlike previous studies, no significant differences in $\dot{\mathrm{V}} \mathrm{O}_{2}\left(\mathrm{lmin}^{-1}, \mathrm{ml} \mathrm{kg}^{-1} \mathrm{~min}^{-1}\right) \dot{\mathrm{V}} \mathrm{E}\left(1 \mathrm{~min}^{-1}\right), \dot{\mathrm{V}} \mathrm{CO}_{2}\left(1 \mathrm{~min}^{-1}\right)$ or heart rate $\left(\mathrm{b} \min ^{-1}\right)$ were found between the two modes of ergometry during the last minute of incremental exercise to exhaustion in a homogenous group of $\mathrm{T} 4-\mathrm{T} 6$ paraplegic men. In addition the present results indicate that the term $\dot{\mathrm{VO}}_{2}$ max should be used to describe the maximum rate of oxygen consumption in paraplegic subjects.
\end{abstract}

Keywords: arm crank; oxygen consumption; wheelchair propulsion; paraplegia; thoracic spinal cord injury

\section{Introduction}

Maximal oxygen consumption $\left(\mathrm{V}_{2}\right.$ max $)$, is a reliable and valid measure, and is achieved when the maximum amount of available muscle mass is activated, eg when uphill treadmill running. During incremental cycle and arm crank exercise to exhaustion, the highest $\dot{\mathrm{VO}}_{2}$ obtained is $90-95 \%$ and $68-73 \%^{1}$ respectively of the uphill treadmill running value and is traditionally referred to as $\mathrm{VO}_{2}$ peak.

The relationship between available muscle mass and the highest $\dot{\mathrm{V}}_{2}$ attained can be modified by specific endurance training. For example highly trained rowers are reported to have a higher $\mathrm{VO}_{2}$ at exhaustion during rowing than during cycle exercise. ${ }^{2}$ Similarly highly trained cyclists may reach an equivalent $\dot{\mathrm{VO}}_{2}$ on the cycle ergometer as during incremental uphill treadmill running. ${ }^{3}$ While the concepts of $\dot{\mathrm{V}}_{2} \max$ and $\dot{\mathrm{V}} \mathrm{O}_{2}$ peak are widely understood and readily accepted in studies with able bodied subjects this is not the case for spinally injured subjects.

Studies using spinally injured subjects have compared maximum physiological responses during arm crank and stationary wheelchair ergometry ${ }^{4-7}$ and, although the $\dot{\mathrm{V}} \mathrm{O}_{2}$ at exhaustion was not significantly different between the two ergometers, there was a significantly higher power, ${ }^{4,5}$ heart rate ${ }^{4,6,7}$ and lactate concentration $^{4,7}$ during arm crank exercise. Conversely, Gass and Camp ${ }^{8}$ compared arm cranking with unrestrained wheelchair propulsion on a treadmill in a group of paraplegic men with varying levels of spinal lesion (T5-L4) and found that oxygen consumption $\left(\dot{V}^{\circ} \mathrm{O}_{2}\right)$, ventilation $\left(\dot{\mathrm{V}}_{\mathrm{E}}\right)$, carbon dioxide production $\left(\mathrm{VCO}_{2}\right)$ and heart rate (HR) were all significantly higher at exhaustion during unrestrained wheelchair propulsion than during arm cranking exercise. These authors argued that the highest oxygen consumption obtained during wheelchair propulsion should be referred to as $\dot{\mathrm{V}} \mathrm{O}_{2}$ max rather than $\dot{\mathrm{VO}}_{2}$ peak, since in these spinally injured subjects, unrestrained wheelchair propulsion, rather than arm cranking, activated the maximum amount of available muscle mass.

Others have also compared wheelchair propulsion on a motor driven treadmill with arm cranking and found a significantly higher HR during wheelchair propulsion, but no significant differences in $\dot{\mathrm{VO}}_{2} \mathrm{lmin}$, or $\mathrm{ml} \mathrm{kg}{ }^{-1} \min ^{-1} .{ }^{9}$ The apparent discrepancies among studies suggested a re-examination of previous results to determine if the reported differences could be due to factors other than the choice of ergometer. Earlier studies in this area have used a variety of ergometers, 
some with questionable relevance to wheelchair propulsion, often confounded by a heterogeneity of subjects and lesion levels ${ }^{4-6}$ thereby confusing the influence of the ergometer per se upon the resultant physiological response. In order to clarify the validity of common ergometers used for spinally injured subjects it was decided to re-examine the hypothesis that unrestrained wheelchair propulsion on a motor driven treadmill would result in significantly higher physiological responses at exhaustion than arm crank exercise in a homogenous group of T4-T6 paraplegic men.

\section{Methods}

Nine men with traumatic, clinically complete spinal cord lesions between levels T4 and T6 volunteered to participate in this study which had been approved by a duly constituted institutional ethics committee. After being informed about the study, including the risks and benefits, and attending a familiarisation session, written consent was obtained from each subject in accordance with procedures prescribed by the National Health and Medical Reseach Council (NH \& MRC). Subjects were required to make three visits to the laboratory. At the first visit each subject underwent a medical examination, including a neurological examination to determine the level and degree of motor and sensory completeness of the spinal cord lesion. All subjects were asked to complete a questionnaire about the cause and date of their spinal cord lesion and their current level of physical activity. The reported levels of physical activity were then ranked on a scale from one to four with one representing involvement in activities of daily living only, two involvement in regular light exercise, three involvement in moderate regular exercise, and four representing daily participation in some form of strenuous exercise. Following the medical examination each subject, dressed in track suit trousers, was weighed to the nearest $0.1 \mathrm{~kg}$, and their supine height was measured to the nearest $1 \mathrm{~mm}$ on a Holtain stadiometer. Skinfold thickness measurements were taken in triplicate at biceps, triceps and subscapular sites, averaged and then summed to provide an estimate of adiposity. Following the anthropometry each subject was again familiarised with the head gear, mouth piece and nose clip, and given an appropriate practice on both the motor driven treadmill and the arm crank ergometer.

Approximately 5 days later each subject returned to the laboratory and underwent an incremental exercise test to exhaustion either by arm cranking or by pushing their wheelchair on a motor driven treadmill. Approximately 3-7 days later, the second of the two randomly allocated incremental exercise tests was completed.

The protocol for the incremental wheelchair propulsion test required subjects to propel their 'sports' wheelchair on a motor driven treadmill. After a three min warm up a $3.5 \mathrm{~km} \mathrm{~h}^{-1}, 0 \%$ grade, increases in either speed $\left(0.5 \mathrm{~km} \mathrm{~h}^{-1}\right)$ or grade $(0.5 \%)$ occurred every $30 \mathrm{~s}$ until a gradient of $4 \%$ was reached, after which further increments in power were achieved by
$30 \mathrm{~s}$ increases in speed $\left(0.5 \mathrm{~km} \mathrm{~h}^{-1}\right)$. Small individual variations in treadmill protocol were used to accommodate differences in pushing styles and chair design, particularly at the higher speeds.

For the arm crank exercise test, subjects were required to arm crank a modified electronic cycle ergometer (Siemens 380B) while seated in their wheelchair. The pedal shafts of the ergometer were positioned level with each subject's acromioclavicular joints and subjects were asked to maintain a pedal frequency of approximately 50 revolutions per minute. The incremental arm crank test commenced with three min warm up at 20 watts (W), and the power was subsequently increased $5 \mathrm{~W}$ every $30 \mathrm{~s}$ until volitional fatigue. Near volitional fatigue subjects were verbally encouraged to continue exercising in an attempt to elicit the highest possible $\dot{\mathrm{VO}} \mathrm{O}_{2}$.

During all incremental exercise tests, subjects breathed through a low resistance valve (Hans Rudolf model 2700) and expired gas was directed thiough a heated pneumotach into a 31 mixing chamb\&r. Ametek $\mathrm{O}_{2}$ and $\mathrm{CO}_{2}$ analysers continuously s?mpled mixed expired gas from the distal end of the mixing chamber and computer calculations were made every $20 \mathrm{~s}$ of oxygen uptake $\left(\dot{\mathrm{V}} \mathrm{O}_{2} \mathrm{ml} \mathrm{kg}^{-1} \mathrm{~min}^{-1}, 1 \mathrm{~min}^{-1} \mathrm{STPD}\right) \mathrm{ex}-$ pired minute ventilation $\left(\dot{V}_{\mathrm{E}} 1 \mathrm{~min}^{-1}\right)$ and carbon dioxide production $\left(\dot{\mathrm{VO}}_{2} 1 \mathrm{~min}^{-1}, \mathrm{STPD}\right)$. All experiments were conducted in a controlled environment at $23^{\circ} \mathrm{C}$ dry bulb (DB); $18^{\circ} \mathrm{C}$ wet bulb) (WB).

Throughout each incremental exercise test, heart rate (HR) was monitored continuously from a CM5 electrode placement and this information was stored in an IBM compatible computer, averaged and displayed each minute. It has been previously found in the authors' laboratory that electrical activity from chest muscles, particularly during wheelchair propulsion, may be incorporated into the ECG producing an incorrect computer estimate of the exercise heart rate. Therefore, paper recordings of the electrocardiogram (ECG) were obtained prior to exercise, during the last $10 \mathrm{~s}$ of each minute of exercise, at the completion of exercise, or whenever visual inspection of the screen indicated interference with the ECG trace and, where necessary, the paper recording was used to determine HR.

\section{Statistical analysis}

Means and standard errors were calculated for all variables. The highest values obtained during the last minute of exercise for the two modes of ergometry were compared using paired $t$ tests. The results were accepted as being statistically significant at $P<0.05$.

\section{Results}

Eight subjects were paraplegic secondary to trauma and one subject secondary to transverse myelitis. All subjects' spinal cord lesions were between T4 and T6 and, although all subjects were deemed to have clinically complete spinal cord lesions, two subjects were found to have a small amount of sensation 
(hot/cold) in one or both legs. All subjects were motor complete. Most subjects were taking medication, none of which was expected to significantly interfere with their exercise response. The subjects were aged $30.8 \pm 2.4$ years and had been in wheelchairs for $8.5 \pm 3.0$ years.

The overall habitual level of physical activity of the subjects was low with one subject being level 4 , two subjects level 3 , one subject level 2 and five subjects level1.

The body mass at the time of arm cranking and wheelchair propulsion exercise was $70.2 \pm 3.4$ and $70.1 \pm 3.3 \mathrm{~kg}$ respectively, and this difference was not significant, $(P>0.05)$. The averaged sum of skinfold thickness measured at three sites (triceps, biceps and subscapular) was $28 \pm 3 \mathrm{~mm}$. Supine height was $170 \pm 2 \mathrm{~cm}$.

The physiological responses during the final minute of arm cranking and unrestrained wheelchair propulsion on a motor driven treadmill are shown in Table 1. The highest $\dot{\mathrm{V}}_{2}\left(\mathrm{lmin}^{-1}\right)$ recorded during the final minute of the arm cranking and wheelchair treadmill exercise was $1.65 \pm 0.14$ and $1.72 \pm 0.101 \mathrm{~min}^{-1}$, respectively and, relative to body weight, $23.8 \pm 2.0$ and $24.8 \pm 1.7 \mathrm{ml} \mathrm{min}^{-1} \mathrm{~kg}^{-1}$. There was no significant difference between the highest $\mathrm{VO}_{2}\left(\mathrm{lmin}^{-1} \mathrm{ml}\right.$ $\left.\mathrm{min}^{-1} \mathrm{~kg}^{-1}\right)$ during the last minute for the two modes of exercise $(P>0.05)$. The maximum $\dot{V}_{\mathrm{E}}(\mathrm{STPD})$ during arm cranking and wheelchair propulsion was $52.0 \pm 6.6$ and $56.1 \pm 4.81 \mathrm{~min}^{-1}$, respectively and this difference was also not significant $(P>0.05)$. The heart rates $\left(\mathrm{b} \mathrm{min}^{-1}\right)$ and $\dot{\mathrm{V}} \mathrm{CO}_{2}\left(\mathrm{l} \mathrm{min}^{-1}\right)$ at exhaustion for the arm cranking and wheelchair treadmill test were $177 \pm 3$ and $177 \pm 4 \mathrm{~b} \mathrm{~min}^{-1}$, and $2.00 \pm 0.20$ and $2.00 \pm 0.121 \mathrm{~min}^{-1}$ respectively. No significant differences were observed for $\dot{\mathrm{V}} \mathrm{CO}_{2}\left(\mathrm{l} \mathrm{min}^{-1}\right)$ or heart rate at exhaustion during the two modes of ergometry $(P>0.05)$.

\section{Discussion}

Ergometry is, by definition, the method of quantifying work. In physiological studies ergometry is used to

Table 1 Physiological responses during the final minute of arm cranking and wheelchair propulsion in T4-T6 paraplegic subjects $(\overline{\mathrm{X}} \pm \mathrm{SE})$

\begin{tabular}{|c|c|c|c|}
\hline & $\begin{array}{c}\text { Arm } \\
\text { cranking }\end{array}$ & $\begin{array}{l}\text { Wheelchair } \\
\text { propulsion }\end{array}$ & $P$ \\
\hline $\begin{array}{l}\dot{\mathrm{V}}_{\mathrm{E}} \mathrm{STPD} \\
.\left(1 \mathrm{~min}^{-1}\right)\end{array}$ & $52.0 \pm 6.6$ & $56.1 \pm 4.8$ & NS \\
\hline $\begin{array}{l}\mathrm{VO}_{2} \\
\left(1 \operatorname{lmin}^{-1}\right)\end{array}$ & $1.65 \pm 0.14$ & $1.72 \pm 0.10$ & NS \\
\hline 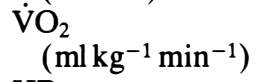 & $23.8 \pm 2.0$ & $24.8 \pm 1.7$ & NS \\
\hline $\begin{array}{l}\mathrm{HR} \\
\left(\mathrm{b} \min ^{-1}\right)\end{array}$ & $177 \pm 3$ & $177 \pm 4$ & NS \\
\hline
\end{tabular}

$P<0.05$; NS: not significant deliver measured amounts of work in order to study physiological responses. The choice of ergometer to study physiological responses of spinal cord injured individuals has been problematic and has resulted in healthy debate about modes of upper body exercise and differing physiological responses. ${ }^{4-9}$ Explanation of these differences could be provided by examining the subject, the ergometers, and the criteria for the decision of $\dot{\mathrm{V}}_{2} \mathrm{max} /$ peak.

The present study compared the highest physiological responses during arm crank exercise and unrestrained wheelchair propulsion on a motor driven treadmill in a group of motoric complete T4-T6 paraplegic men and found that therf ore no significant differences in $\dot{\mathrm{VO}} \mathrm{O}_{2} 1 \mathrm{~min}^{-1}, \mathrm{ml} \mathrm{hun}^{-1} \mathrm{~kg}^{-1}, \dot{\mathrm{V} C O} \mathrm{CO}_{2}$ $1 \mathrm{~min}^{-1}, \dot{\mathrm{V}}_{\mathrm{E}} 1 \mathrm{~min}^{-1} \mathrm{STPD}$ and HR $\mathrm{b} \mathrm{min}^{-1}$. These results are contrary to our previous results ${ }^{8}$ but consistent with the results of others. ${ }^{5}$ In our previous investigation $^{8}$ significantly higher $\dot{\mathrm{VO}} \mathrm{O}_{2} \quad\left(\mathrm{lmin}^{-1}\right.$, $\left.\mathrm{ml} \mathrm{min}{ }^{-1} \mathrm{~kg}^{-1}\right), \mathrm{VCO}_{2}\left(1 \mathrm{~min}^{-1}\right)$, VE STPD $\left(1 \mathrm{~min}^{-1}\right)$ and HR $\left(\mathrm{b} \mathrm{min}^{-1}\right)$ were found at exhaustion in a group of paraplegic men propelling their wheelchairs on a motor driven treadmill when compared to arm cranking. In that study it was proposed that the higher values obtained during unrestrained wheelchair propulsion were due both to activation of more muscle mass during wheelchair propulsion and the fact that wheelchair propulsion on the treadmill was more specific to everyday ambulation. Those subjects had spinal lesion levels between T5 and L4/S2 resulting from trauma $(n=8)$, transverse myelitis $(n=1)$ and poliomyelitis $(n=1)$, with the degree of motoric and sensory completeness being unreported. In this and other previous studies $^{4-9}$ little or no consideration was given to the possible contributory effect of varying spinal lesion levels upon the physiological responses. Rather it was presumed that the differences in physiological responses were simply due to the different ergometers.

Unlike previous studies ${ }^{4-9}$ the subjects in the present study had motoric complete spinal cord lesion levels between $\mathrm{T} 4$ and $\mathrm{T} 6$. It could be argued that with this homogenous level of disability and motor ability a similar amount of available and active muscle mass was utilised during both arm cranking and wheelchair propulsion, resulting in similar physiological responses at exhaustion.

In some earlier studies ${ }^{4,6,7}$ both the arm crank and wheelchair ergometers were modified Monark cycle ergometers relying integrally upon pedal revolutions for their power output. Despite such a limitation, particularly during the final minutes of a maximal incremental exercise test, these studies found significantly higher heart rate,${ }^{4,6,7}$ power, ${ }^{4}$ and lactate ${ }^{4,7}$ during arm cranking in the absence of any significant difference in $\mathrm{V}_{2}$. The finding of significantly higher physiological responses during arm cranking is inconsistent with the results of the present study. The present study used a homogenous group of paraplegic men (T4-T6, motor complete) and an electronically braked arm cranker with power largely independent of pedal revolutions. It is quite possible that the differences in 
results between the present study and others could have been due to variability of subjects included in previous experimental groups and the use of mechanically braked ergometers.

The highest (maximal) oxygen consumption achieved by able bodied subjects running uphill is known as $\mathbf{V O}_{2}$ max and signifies a plateau in physiological strain. When able bodied subjects perform upper body exercise to exhaustion the highest $\mathrm{VO}_{2}$ achieved is approximately $65 \%$ of the $\mathrm{VO}_{2} \max ^{1}$ and accordingly, is called $\dot{\mathrm{VO}} 2$ peak.

If spinally injured subjects exercise to exhaustion with their upper body either during wheelchair propulsion on a treadmill or arm cranking and providing they activate the maximum amount of available muscle mass, the oxygen consumption attained at exhaustion should be called $\dot{\mathrm{V}} \mathrm{O}_{2}$ max. Under such circumstances, the use of the term $\mathrm{VO}_{2}$ peak suggests that paraplegic subjects are capable of activating further available muscle mass, eg lower body. If one accepts the argument that $\dot{\mathrm{VO}}{ }_{2}$ max reflects the maximum oxygen that the body can consume, then the highest value should be called maximum, whether it be in paraplegic or able bodied subjects. In able bodied subjects during uphill treadmill running the decision whether maximum $\mathrm{VO}_{2}$ has been attained depends upon demonstrating a 'plateau' in oxygen consumption in response to increasing demand. ${ }^{10,11}$ Typically with lower body exercise the plateau in $\mathrm{VO}_{2}$ is defined when successive minute measures of $\dot{\mathrm{VO}} \mathrm{O}_{2}$ differ by less than $0.15 \mathrm{l}$ in response to increments in power expected to produce a $\dot{\mathrm{VO}}_{2}$ greater than $0.151 \mathrm{~min}^{-1}$. Applying the same absolute criterion $\left(0.151 \mathrm{~min}^{-1}\right)$ to upper body exercise, may contribute to the difficulty in reaching a plateau in oxygen consumption even though no further increases in cardiac output and arteriovenous oxygen difference occur.

In the present study the difference in $\dot{\mathrm{V}} \mathrm{O}_{2}$ over the final 2 min for arm cranking and wheelchair propulsion was $0.07 \pm 0.02$ and $0.21 \pm 0.031 \mathrm{~min}^{-1}$ respectively.

In light of the results of the present study and the results of others, it may be time to consider applying a relative (eg $4 \%)$ rather than an absolute $\left(0.151 \mathrm{~min}^{-1}\right)$ criterion to successive minute values of $\dot{\mathrm{VO}}{ }_{2}$ during upper body exercise to determine if a plateau has been reached. Indeed, it may be timely to re-examine how the criterion of a plateau in $\mathrm{VO}_{2}$ was established for upper and lower body exercise.

\section{Conclusions}

The present study compared the exercise responses during maximum wheelchair propulsion and arm cranking exercise in a homogenous group of male paraplegic subjects with complete lesion levels from T4-T6 and found no significant differences in $\dot{\mathrm{V}} \mathrm{O}_{2}, \dot{\mathrm{V}}_{\mathrm{E}}, \dot{\mathrm{V}} \mathrm{CO}_{2}$ or $\mathrm{HR}$ at exhaustion between ergometers. High level paraplegic subjects are probably unable to recruit a significantly larger muscle mass during wheelchair propulsion exercise than during arm cranking and hence arm crank ergometry is a valid method of measuring $\dot{\mathrm{V}} \mathrm{O}_{2}$ max and related variables in such subjects. It is recommended that the term $\dot{\mathrm{VO}}_{2} \max$ be used to describe the maximum rate of oxygen consumption obtainable in paraplegic subjects, with consideration being given as to whether or not the accepted criterion for $\dot{\mathrm{V}} \mathrm{O}_{2}$ max has been achieved.

\section{References}

1 Berg U, Kanstrup IL, Ekblom B. Maximal oxygen uptake during exercise with various combinations of arm and leg work. J Appl Physiol 1976; 41: 191-196.

2 Secher NH, Vaage O, Jensen K, Jackson RC. Maximal aerobic power in oarsmen. Eur J Appl Physiol 1983; 51: 155-162.

3 Coyle EF, Coggan AR, Hopper MK, Waters TJ. Determinants of endurance in well trained cyclists. J Appl Physiol 1988; 64: 2622-2630.

4 Glaser RM, Sawka MN, Brune MF, Wilde SW. Physiological responses to maximal effort wheelchair and arm crank ergometry. J Appl Physiol 1980; 48: 1060-1064.

5 Martel G, Noreau L, Jobin, J. Physiological responses to maximal exercise on arm cranking and wheelchair ergometer with paraplegics. Paraplegia 1991; 29: 447-456.

6 Wicks JR, Lymburner K, Dinsdale SM, Jones NL. The use of multistage exercise testing with wheelchair ergometry and arm cranking in subjects with spinal cord lesions. Paraplegia 1977; 15: 251-261.

7 Gayle GW, Pohlman RL, Glaser RM, Davis GM. Cardiorespiratory and perceptual responses to arm crank and wheelchair exercise using various handrims in male paraplegics. Res $Q$ Exerc Sports 1990; 61: 224-232.

8 Gass GC, Camp EM. The maximum physiological responses during incremental wheelchair and arm cranking exercise in male paraplegics. Med Sci Sports Exerc 1984; 16: 355-359.

9 McConnell TJ, Horvat MA, Beutel-Horvat TA, Golding LA. Arm crank versus wheelchair treadmill ergometry to evaluate the performance of paraplegics. Paraplegia 1989; 27 307-313.

10 Taylor HL, Buskirk E, Henschel A. Maximum oxygen intake as an objective measure of cardiorespiratory fitness. J Appl Physiol 1958; 8: 73-80.

11 Mitchell JH, Sproule BJ, Chapman CB. Physiological meaning of the maximal oxygen intake test. J Clin Invest 1958; 37: 538. 